\title{
Synthesis of Coccinia grandis (L.) Voigt extract's silver nanoparticles and it's in vitro antidiabetic activity
}

\author{
Yasmin H. Momin ${ }^{1 *}$ (D), Veerendra C. Yeligar ${ }^{2}$ \\ ${ }^{1}$ Annasaheb Dange College of B.Pharmacy, Ashta, 416301, Maharashtra, India. \\ ${ }^{2}$ KIMSDU'S Krishna Institute of Pharmacy, Karad, 415539, Maharashtra, India.
}

\begin{tabular}{l}
\hline ARTICLE INFO \\
\hline Received on: $27 / 02 / 2021$ \\
Accepted on: $26 / 04 / 2021$ \\
Available online: $05 / 08 / 2021$
\end{tabular}

\section{Key words:}

Green synthesis, silver nanoparticles, SAED, in vitro antidiabetic activity, Coccinia grandis (L.) Voigt.

\begin{abstract}
The development of ecofriendly methods for synthesis of metallic nanoparticles (NPs) is an important step in the field of Nano biotechnology and Nanoscience. NPs are synthesized by various methods but are hazardous to ecosystem and expensive. Hence, there is need to develop nontoxic, ecofriendly, and less expensive procedures for synthesis of NPs with the ideal morphologies. The present study aimed to synthesize silver nanoparticles (AgNPs) of Coccinia grandis (L.) Voigt hydroalcoholic stem extract and investigate the in vitro antidiabetic activity. AgNPs were synthesized by reducing the silver ions of silver nitrate solution by the hydroalcoholic extract of C. grandis (L.) Voigt stem. Formation of deep brown color qualitatively confirms synthesis of AgNPs which was further confirmed by UVVisible spectroscopy, Fourier transform infrared spectroscopy, particle size analysis, zeta potential, and HR-TEM. These AgNPs exhibited UV visible absorptions in the range of 400-450 nm; High resolution transmission electron microscopy demonstrated AgNPs particle size at $20 \mathrm{~nm}$. In vitro antidiabetic activity was evaluated for these AgNPs and found potent to reduce blood sugar level. The AgNPs of C. grandis (L.) Voigt stem extract showed remarkable in vitro antidiabetic activity and can be used as vehicle in drug transportation and in the targeted drug delivery system.
\end{abstract}

\section{INTRODUCTION}

In the field of nanotechnology and nanoscience nanoparticulate drug delivery system is used in the design, characterization, development, formulation of materials, structures, devices, and systems using nanoscales (Ramaswamy et al., 2015). Nanoparticles (NPs) provide new properties like particle size; distribution morphology, chemical reactivity, and optical behavior compared to larger particles. NPs are arranged in the layers on surfaces which provide larger surface area and hence more catalytic reactivity.

A significant step in nanobiotechnology and nanoscience is to establish coherent and eco-friendly methods for the synthesis of metallic nanoparticles. NPs are synthesized by various methods like chemical, physical, and biological methods (Kharissova et al., 2013), but most of them are hazardous to the ecosystem

\section{"Corresponding Author}

Yasmin Hamid Momin, Annasaheb Dange College of B. Pharmacy, Ashta, India.E-mail: mullays413@gmail.com and expensive. Therefore, a scientist looking for new method for production of NPs, among which biosynthesis of nanoparticles extend great attention due to its nontoxic, eco-friendly, and economic advantages with the desired morphologies and sizes. Natural resources, such as the use of microorganisms, plants, enzymes, and biological systems, are the best choices for achieving this goal. Biological methods of nanoparticles synthesis provide an eco-friendly, nontoxic approach over chemical method (Benakashani et al., 2016; Varghese et al., 2019). The chemical method utilizes use of toxic chemicals in various metallic nanoparticles synthesis. Silver nanoparticles (AgNPs) exhibited many pharmacological activities like antimicrobial, anticancer, antiparasitic, antidiabetic, and antioxidant activities (Lakshmanan et al., 2018). Applications of nanoparticles depend upon the size, shape, and size distribution (Abou El-Nour et al., 2010).

Green synthesis of nanoparticles evolved with specific self-assembly properties, size shape, surface structure, the greater surface to volume ratio, and biocompatibility (Govindappa et al., 2018). The literature study and epidemiological studies strongly support that oral antidiabetic drugs fail to prevent major complications of diabetes mellitus like diabetic neuropathy, 
diabetic nephropathy, atherosclerosis, foot infection, and obesity. But nanoparticles can interact with a human body at a molecular level with a greater degree of specificity and potential to get translated into targeted cells and tissue with minimum side effects and maximal therapeutic effects. The complexation of metal nanoparticles by using natural plants was a very promising area in nanotechnology (Kharissova et al., 2013).

Synthesis of AgNPs is possible due to biomolecules like amino acids, proteins, enzymes, coenzymes, flavonoids, terpenoids, alkaloids, polysaccharides, tannins, saponins, phenolic, and vitamins. These biomolecules contribute electrons for the reduction of $\mathrm{Ag}^{+}$ions forming $\mathrm{AgNPs}$. AgNPs can be synthesized using plant materials like bark, roots, stems, fruit, seeds, callus, peels, leaves, and flowers in a variety of geometrical shape sand sizes (Rai et al., 2009). The AgNPs exhibited particle size between 1 and $100 \mathrm{~nm}$.

Green nano synthesis triggers a novel era in the treatment of diabetes mellitus and its linked major complications due to ease of biodegradability. A phytoconstituent reported in C. grandis (L.) Voigt contains Heptacosane, Cephalandrol, tritriacontane, Beta-sitosterol alkaloids Cephalandrine A, and Cephalandrine B. Thus, the AgNPs of stem extract of $C$. grandis (L.) Voigt was synthesized and characterized by UV Spectrometry, Fourier transform infrared spectroscopy (FTIR), Particle size analyzer with zeta potential, transmission electron microscopy (TEM), selected area electron diffraction (SAED) (Malapermal et al., 2017). The flavonoids, phenolic compounds, terpenoids, saponins, and phytosterol present in the plant can reduce blood glucose level and oxidative stress. Hence, further these nanoparticles were evaluated by in vitro alpha-amylase inhibitory assay and glucose uptake assay (Gupta et al., 2009; Nair et al., 2013). Alpha-amylase is responsible for the breakdown of starch to glucose. Inhibition of alpha amylase delays the absorption of glucose and can maintain the blood glucose level in hyperglycemic individuals (Banerjee et al., 2017).

Coccinia grandis (L.) Voigt is one of the perennial creeper or climber Cucurbitaceae plants. This plant grows up to $13 \mathrm{~cm}$ tall, covering small trees, poles, and houses. It is popularly referred as Ivy gourd or scarlet gourd or kowai fruit or kundru. It is composed of five glabrous and broad lobed leaves. The leaves of C. grandis (L.) Voigt are pentagon in shape having a hairy lower surface and the upper surface is hairless. At the apex, the seeds are rounded, yellowish-grey, ovoid, and compact. Flowers are 2-3 cm long, with female and male flowers appearing on the petiole at the axils and having three stamens. With a fibrous fracture, $C$. grandis (L.) has a long, dense, and tuberous root (Tamilselvan et al., 2011). Young stem is smooth, green in color, and slender, but it becomes large, swollen, and glabrous when matured. The various parts of the C. grandis (L.) Voigt was being used for diabetes mellitus, (Meenatchi et al., 2017) bronchitis, urinary tract infection, ulcer, microbial infection, and oxidative stress.

To the extent of our literature survey, flower, leaves, and fruits were used for AgNPs synthesis but Stem part of hydroalcoholic extract of $C$. grandis (L.) was not used for AgNPs synthesis and its antidiabetic evaluation. Hence, in the current study, we focused green AgNPs synthesis using hydro alcoholic stem extract of $C$. grandis (L.) Voigt with its in vitro antidiabetic activity.

\section{MATERIALS AND METHODS}

\section{Chemicals}

Porcine pancreas alpha amylase, Heparin, 3,5 Dinitro salicylic acid, silver nitrate, glucose oxidase-peroxidase (GODPOD), acarbose, and metformin were purchased from Sisco Research Pvt. Ltd. Mumbai and sodium hydroxide $(\mathrm{NaOH})$, methanol, petroleum ether ethyl acetate, glucose, sodium potassium tartarate, and starch were procured from Unique Biological and Chemicals Kolhapur. All chemicals used were of an analytical grade.

\section{Plant material}

The stem parts of $C$. grandis (L.) Voigt was gathered from local areas of Sangli (Maharashtra) in October 2018. The herbarium specimen of plant was identified \& authenticated by Dr. Ingale Priyanka (Scientist C) from Botanical Survey of India Pune (The voucher specimen number is BSI/WRC/IDEN.CER./2019/H3/138).

\section{Preparation of extract}

The dried pieces of stems were crushed in an electrical grinder and made coarse powder for further extraction. $500 \mathrm{gm}$ coarse powder was subjected to soxhlet extractor by continuous hot successive extraction method using petroleum ether; chloroform and ethyl acetate, respectively, to make sure extraction of wide variety of phytochemicals with different polarity. Petroleum ether solubilized more non-polar lipids. The filtrate obtained from continuous hot extraction of each solvent was evaporated to dryness. Further resultant marc was macerated with hydroalcoholic mixture (Water: Methanol, 80:20 and 20:80). The filtrates obtained were combined together and was evaporated to dryness. The yield of hydro alcoholic extracts was $10 \mathrm{gm}$.

\section{Synthesis of AgNPs using hydro alcoholic stem extract of $C$. grandis (L.) Voigt plant}

Silver nitrate solution $(0.01 \mathrm{M})$ has been prepared in the distilled water. Aqueous solution of stem extract containing $10 \mathrm{mg} / 10 \mathrm{ml}, 20 \mathrm{mg} / 10 \mathrm{ml}$ and $30 \mathrm{mg} / 10 \mathrm{ml}$ concentration were prepared. To the $4 \mathrm{ml}$ of $10 \mathrm{mg} / 10 \mathrm{ml}, 20 \mathrm{mg} / 10 \mathrm{ml}$ and $30 \mathrm{mg} / 10$ $\mathrm{ml}$ aqueous stem extract solution, $30 \mathrm{ml}$ of $0.01 \mathrm{M}$ silver nitrate solution was added. The solution was incubated for 24 hours in dark state. Changes in color of solution confirmed the formation of AgNPs. Colorless solution turned to deep brown indicating synthesis of AgNPs (Fig. 1).

\section{Lyophilization of nano suspension}

Synthesized nano suspension was converted into the dry powder by using laboratory scale lyophilizer (Labconco free zone 2.51 ) for 48 hours at predetermined conditions. The freeze dried product was placed in air tight container for further characterization.

\section{Characterization of AgNPs}

\section{$U V$-visible spectrophotometry}

Metallic nanoparticles can be characterized by the UVvisible spectrophotometer (Shimadzu UV Spectrophotometer 1800) in the range of 200-800 $\mathrm{nm}$ by displaying their surface plasmon resonance bands (Chandran et al., 2006; Shah et al., 2012). 


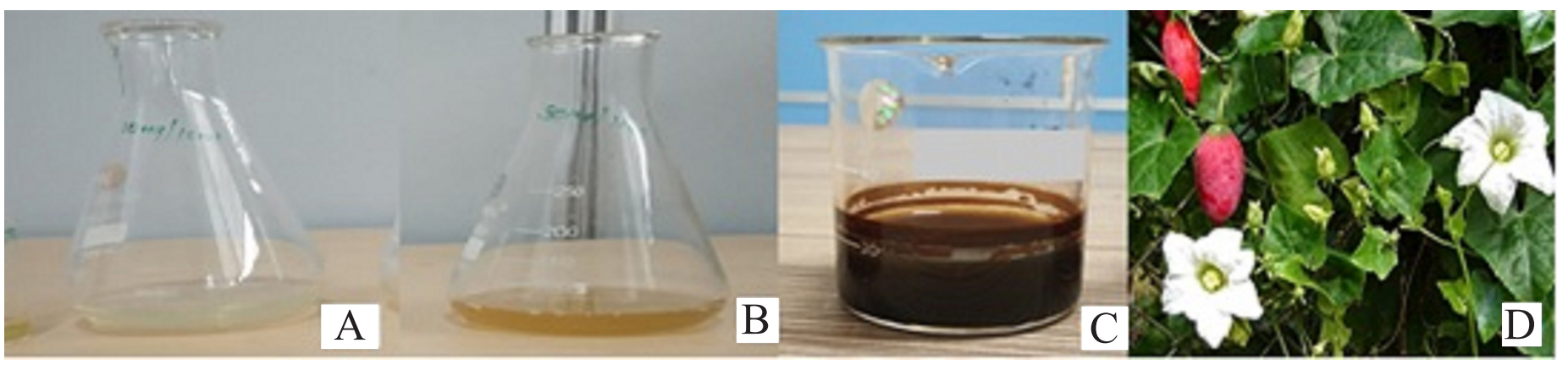

Figure 1. Synthesis of AgNPs by using Coccinia grandis (L.) Voigt stem extract. A: Silver nitrate solution (0.01M); B: Stem extract solution; C: Synthesized AgNPs; D: Coccinia grandis (L.) Voigt.

\section{Fourier transforms infrared spectroscopy}

Fourier transmission infra-red spectrophotometer was used to investigate presence of functional group in synthesized AgNPs. Spectra were recorded on FTIR Spectrophotometer (Agilent Technologies, Cary-630-FTIR Mumbai) with scanning range of about $4,000-400 \mathrm{~cm}^{-1}$.

\section{Particle size distribution and zeta potential}

The mean particle size analysis of AgNPs was carried out using nanoparticles analyzer SZ-100 with a zetasizer (Horiba Scientific, Japan). Zeta potential is a measure of suspension stability dependent on the particle surface charge. The zeta potential was determined by a Laser Doppler Anemometer coupled with Nanoparticles Analyzer SZ-100 (Horiba Scientific, Japan). The samples were properly diluted with de-ionized water before analysis and were assessed in triplicate.

\section{Transmission electron microscopy}

TEM consists of the interaction between the electron beam and the sample to produce an image on a photographic plate. TEM has a higher resolution that helps to determine the exact size, morphology, and shape of the nanoparticles (Stamplecoskie and Scaiano, 2010). Surface morphology of nanoparticles in nano suspensions was observed by TEM (Jeol/JEM 2100).

\section{In vivo antidiabetic activity}

The study was approved and conducted as per the norms of the Institutional Animal Ethics Committee (Appasaheb Birnale College of Pharmacy, Sangli) on 22 January 2018. Reference No. IAEC/ABCP/08/2017-18.

\section{Experimental animals}

Wistar albino rats weighing 200-300 g were obtained from the central animal house of H. S. K. College of Pharmacy and Research Centre, Bagalkot. The animals were housed at room temperature $\left(22^{\circ} \mathrm{C}-28^{\circ} \mathrm{C}\right)$ with $65 \% \pm 10 \%$ relative humidity for 12 hours. dark and light cycle and given standard laboratory feed and water ad libitum.

\section{Treatment groups}

1. Group-I: Control rats were administered with $0.5 \mathrm{ml}$ of $0.9 \%$ saline orally [Non-diabetic].

2. Group-II: Streptozotocin ( $45 \mathrm{mg} / \mathrm{kg}$ body weight) induced diabetic rats.
3. Group-III: Standard drug Glimepiride $(10 \mathrm{mg} / \mathrm{kg}$ body weight) was given to diabetic rats.

4. Group-IV: $250 \mathrm{mg} / \mathrm{kg}$ of Hydro alcoholic extract was given to diabetic rats.

5. Group-V: $500 \mathrm{mg} / \mathrm{kg}$ of Hydro alcoholic extract was given to diabetic rats.

Above treatment was given for 14 days orally.

\section{Estimation of blood glucose}

The acclimatized animals were fasted for 24 hours with water ad libitum, fasted animals were divided into five groups. The blood was withdrawn after 5,10 , and 14 days after the 250 and $500 \mathrm{mg} / \mathrm{kg}$ dose administration. Blood samples were collected from retro-orbital plexus under anesthesia and were centrifuged at 3,000 rpm for 10 minutes to obtain the serum, and used for estimation of glucose by using GOD-POD glucose kit.

\section{Statistical analysis}

All values are expressed as mean \pm standard mean error (SEM), $n=6$ in each, a $p<0.01$ as compared to normal group, * $p$ $<0.05, * * p<0.01, * * * p<0.001$ as compared to control group. One-way analysis of variance (ANOVA) followed by Dunnet's test. The values in parentheses represent $\%$ change glucose level.

\section{In vitro antidiabetic activity}

Glucose uptake assay

Collected $4 \mathrm{ml}$ blood from retro orbital veins of rat eyes and mixed with an anticoagulant (Heparin). The blood cells were washed and suspended with saline phosphate buffer (PBS). The blood suspension was mixed with synthesized AgNPs and incubated for 20 minutes at $37^{\circ} \mathrm{C}$. Glucose $(0.5 \%$ in PBS) was added to the mixture and again incubated for 20 minutes at $37^{\circ} \mathrm{C}$. The blood cells washed with PBS and lysed using $50 \mu \mathrm{l}$ of $0.1 \mathrm{~N}$ $\mathrm{NaOH}$ for 3 minutes and $50 \mu \mathrm{l}$ of $0.1 \mathrm{~N} \mathrm{HCl}$ for 3 minutes. The lysed blood was separated by centrifugation and the glucose content of supernatant was analyzed using GOD-POD method.

Glucose $(\mathrm{mg} / \mathrm{dl})=\frac{\text { Standard Sample }}{\text { Control Sample }} \times 100$

\section{Statistical analysis}

All experiments were carried out in triplicates and experimental results were presented as mean \pm standard error of 
the mean of three parallel measurements. Statistical analysis was performed using one-way ANOVA. Values of $p<0.01$ and $p<$ 0.05 were considered to be statistically significant.

\section{$\alpha$-amylase inhibition assay}

The effect of time and dose on the inhibitory activity of $\alpha$ amylase was performed by Ali et al., (2006) and (Aujla et al., 2012) methods, respectively.

\section{Time-dependent method}

Taken $120 \mu \mathrm{l}$ of the test sample ( $3 \mathrm{mg} / \mathrm{ml}$ for AgNPs and $2 \mathrm{mg} / \mathrm{ml}$ for crude extracts), $480 \mu \mathrm{l}$ of distilled water and 1,200 $\mu \mathrm{l}$ of the potato starch $(0.5 \% \mathrm{w} / \mathrm{v}$ primed in $20 \mathrm{mM}$ PBS $)$ and were mixed with $600 \mu 1 \alpha$ amylase $(0.05 \mathrm{~g}$ of a-amylase prepared in $100 \mathrm{ml}$ ice-cold distilled water); incubated at $25^{\circ} \mathrm{C} \pm 2{ }^{\circ} \mathrm{C}$ for 3 minutes. $200 \mu \mathrm{l}$ sample was removed from the above reaction mixture after every 1 minute and $100 \mu \mathrm{l}$ of Di nitro salicylic acid (DNS) color reagent (96 mM 3, 5-dinitrosalicylic acid, 12 $\mathrm{g}$ sodium potassium tartarate in $8 \mathrm{ml}$ of $2 \mathrm{M} \mathrm{NaOH}$ ) was added in it. The resultant solution was heated for 15 minutes at $85^{\circ} \mathrm{C} \pm$ $2^{\circ} \mathrm{C}$. Furthermore, in this mixture, $900 \mu \mathrm{l}$ of distilled water was added and mixed thoroughly. The absorbance was measured at $540 \mathrm{~nm}$. Instead of the enzyme solution, the blank contained 600 $\mu \mathrm{l}$ of distilled water and test samples were substituted with 120 $\mu \mathrm{l}$ for the control, and thus depicted maximum enzyme activity. The test was conducted in the triplicate. The Following equations were used for the percentage inhibition calculation. First, using Equation (1), the net absorbance was calculated. Second, the percentage $(w / v)$ of maltose produced was determined from the Equation (2) using net absorbance obtained. Last, the percentage inhibition was calculated using Equation (3)

Absorbance at $540 \mathrm{~nm}$ control or AgNPs

$$
=\text { Absorbance of Test }- \text { Absorbance of Blank) }
$$

Percent Reaction $=\frac{\text { Mean Maltose in Sample }}{\text { Mean Maltose in Control }} \times 100$

$\%$ Inhibition $=100-$ Percent reaction

\section{Dose-dependent method}

$1 \mathrm{ml}$ of alpha-amylase $(0.5 \mathrm{unit} / \mathrm{ml})$ prepared in a 20 mM PBS (pH 6.9) was pre-incubated with $1 \mathrm{ml}(0.0002-2 \mathrm{mg} / \mathrm{ml})$ test solution for 30 minutes. By adding $1 \mathrm{ml}$ of potato starch, the reaction was initiated. This prepared solution was incubated for 30 minutes at $25^{\circ} \mathrm{C} \pm 2{ }^{\circ} \mathrm{C}$. Finally, with the addition of $1 \mathrm{ml}$ of DNS reagent, the reaction was stopped. At $85^{\circ} \mathrm{C} \pm 2^{\circ} \mathrm{C}$ in a water bath, the solution was heated for 15 minutes. At room temperature, the tubes were cooled and $9 \mathrm{ml}$ of distilled water was introduced. For the modification of the background absorbance, individual blanks were prepared. Before addition of starch solution, the color reagent was added. For control incubations, The AgNPs were replaced by $1 \mathrm{ml}$ distilled water. The absorbance was observed at $540 \mathrm{~nm}$. As a positive control, standard acarbose was used at concentrations of $0.016-1 \mathrm{mg} / \mathrm{ml}$. The triplicate assay was performed, and the mean absorbance was used to measure the percent alpha-amylase inhibition.
Alpha amylase Inhibition

$=\frac{(\text { Absorbance of Control }- \text { absorbance of sample })}{\text { Absorbance of Control }} \times 100$

\section{Statistical analysis}

All experiments were carried out in triplicates and experimental results were presented as mean \pm standard error of the mean of three parallel measurements. Statistical analysis was performed using one-way ANOVA. Values of $p<0.01$ and $p<$ 0.05 were considered to be statistically significant.

\section{RESULTS AND DISCUSSION}

\section{Characterization of AgNPs}

The synthesis of AgNPs of hydroalcoholic stems extract of $C$. grandis (L.) Voigt was confirmed by spectroscopic methods like UV-Visible Spectrophotometry, FTIR, Particle size analysis, TEM. The secondary metabolites present in stem extract of $C$. grandis (L.) Voigt act as a reducing agents and capping agents for AgNPs.

\section{Uv-visible spectrophotometry}

Due to surface Plasmon resonance property of AgNPs of C. grandis (L.) Voigt stem extract showed maximum absorbance at $445 \mathrm{~nm}$ similarly to previous literature report. The comparative absorbance peaks of hydroalcoholic stem extract (Pink color in Fig. 2) and synthesized AgNPs (Blue color in Fig. 2) were noticed to confirm the formation of AgNPs. AgNPs resulted in brown color due to excitation of surface plasmon vibrations in AgNPs Emam et al., (2017).

\section{Fourier transforms infrared spectroscopy}

FTIR analysis was used to find out functional group present in stem extract and synthesized AgNPs. FTIR spectra of AgNPs illustrated peak in the range of $800-4,000 \mathrm{~cm}^{-1}$ (Fig. 3 ) the comparative FTIR spectra's of plant extract and AgNPs were used to show changes in nature of peak. The shifting of

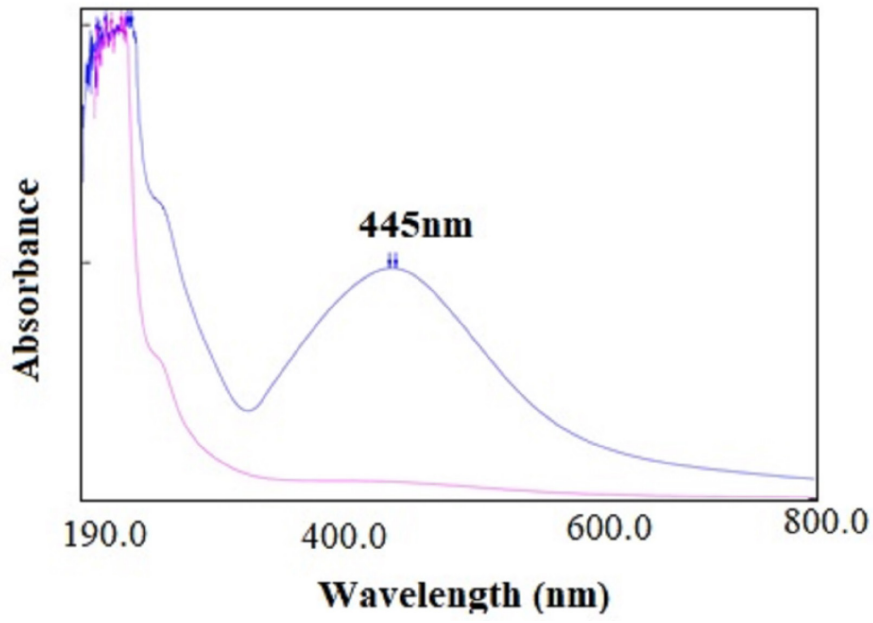

Figure 2. Overlay of absorbance peaks of hydro alcoholic stem extract and synthesized AgNPs 

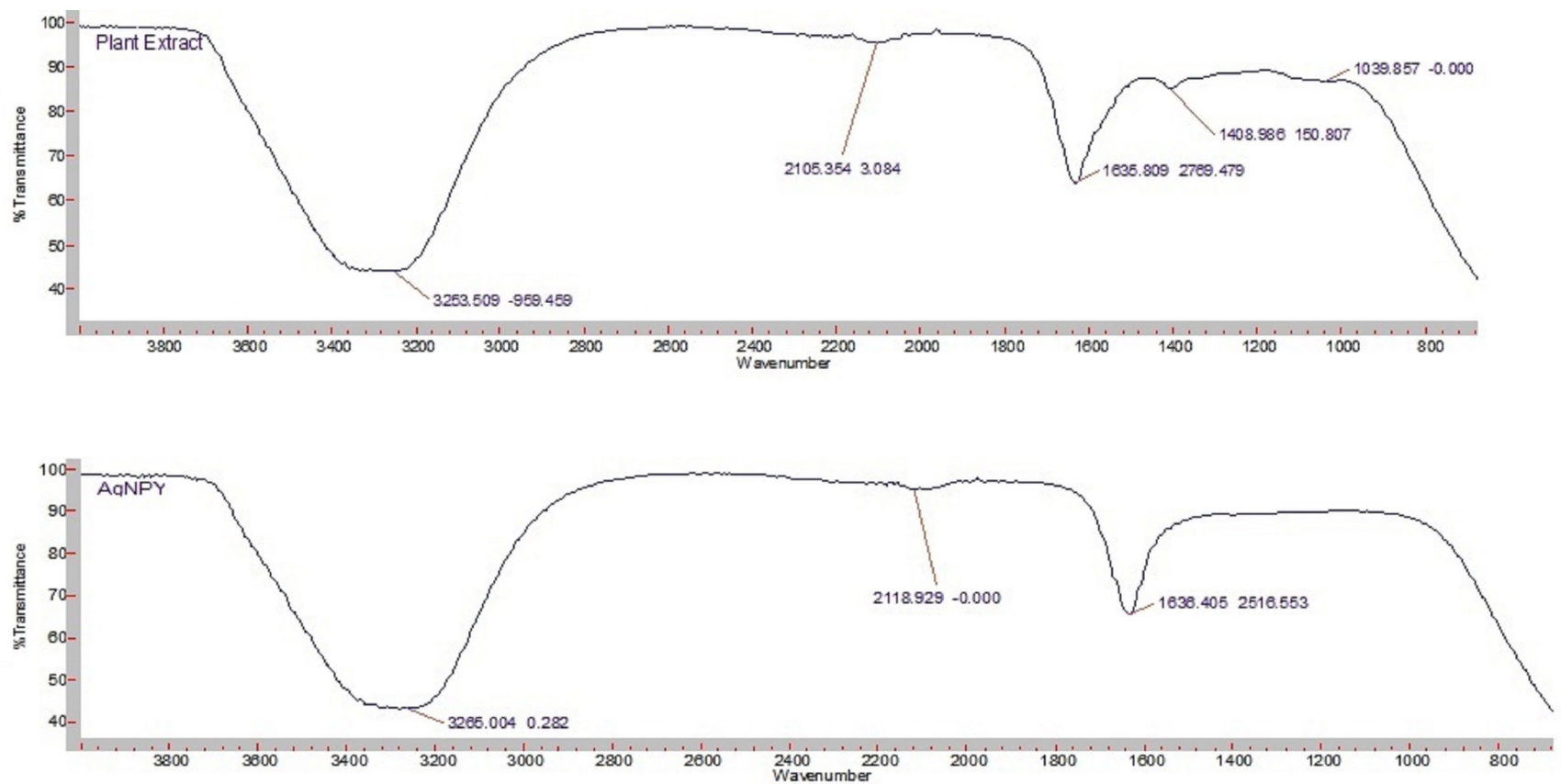

Figure 3. Comparative FTIR analysis of hydro alcoholic stem extract and AgNPs.
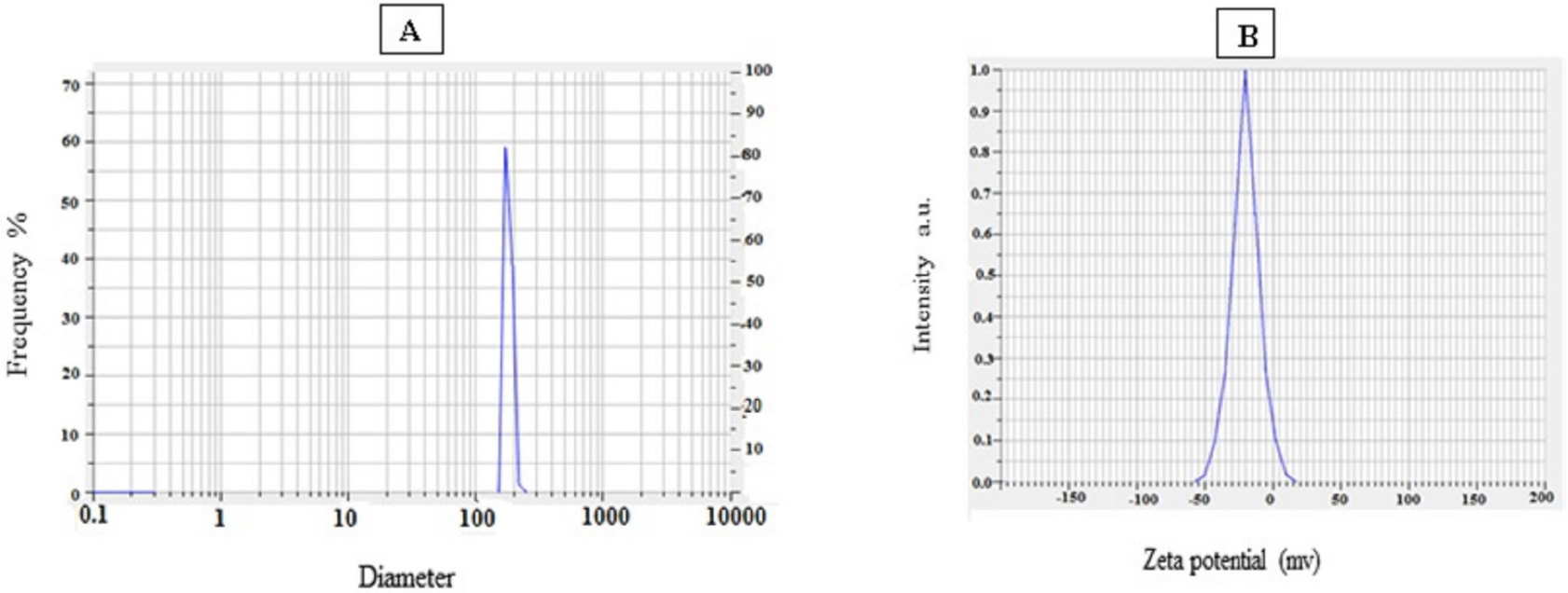

Figure 4. A. Particle size analysis of AgNPs; B. Zeta potential of AgNPs.

peak in AgNPs spectra revealed the formation of nanoparticles. Broad peak at 3,253.50 of plant extract and at 3,265.00 of AgNPs corresponded to $\mathrm{OH}$ stretching vibrations of alcohols and phenols with strong $\mathrm{H}$-bond. Peak at 1,635.80 and at 1,636.40 revealed the presence of $\mathrm{C}=\mathrm{O}$ amide stretching vibrations and presence of phenol or tert alcohol can be confirmed by peak at 1,408 which shows in plane bending of $\mathrm{OH}$ in plant extract. ${ }^{20} \mathrm{It}$ was shifted to $1,510.10$ in AgNPs. The peak at 2,105.35 and at 2,118.92 reflected $\mathrm{CH}$ stretching vibrations in plant extract and AgNPs, respectively.

\section{Particle size distribution and zeta potential}

The mean particle size of synthesized nanoparticles was found to be $154.83 \mathrm{~nm}$ and the Polydispersity index of nanoparticles was 0.3 which is desirable in pharmaceutical nanotechnology. Zeta potential of AgNPs was -22.933 which was sufficient to stabilization nanosuspension (Fig. 4)

\section{Transmission electron microscopy}

TEM images were viewed at different magnifications from $2,000 \times$ to $1,500,000 \times$. From the images of AgNPs were found in the range of 2-100 $\mathrm{nm}$ (Fig. 5). It was noted that there were no aggregation found in nanoparticles. SAED analysis showed that morphologically, AgNPs are spherical and polycrystalline with unique structure.

\section{In vivo antidiabetic activity}

Effect of hydro alcoholic extracts at 250 and $500 \mathrm{mg} /$ $\mathrm{kg}$ on blood glucose level of Streptozotocin induced diabetic rats after $3,5,10$, and 14 day were shown in Table 1 . 

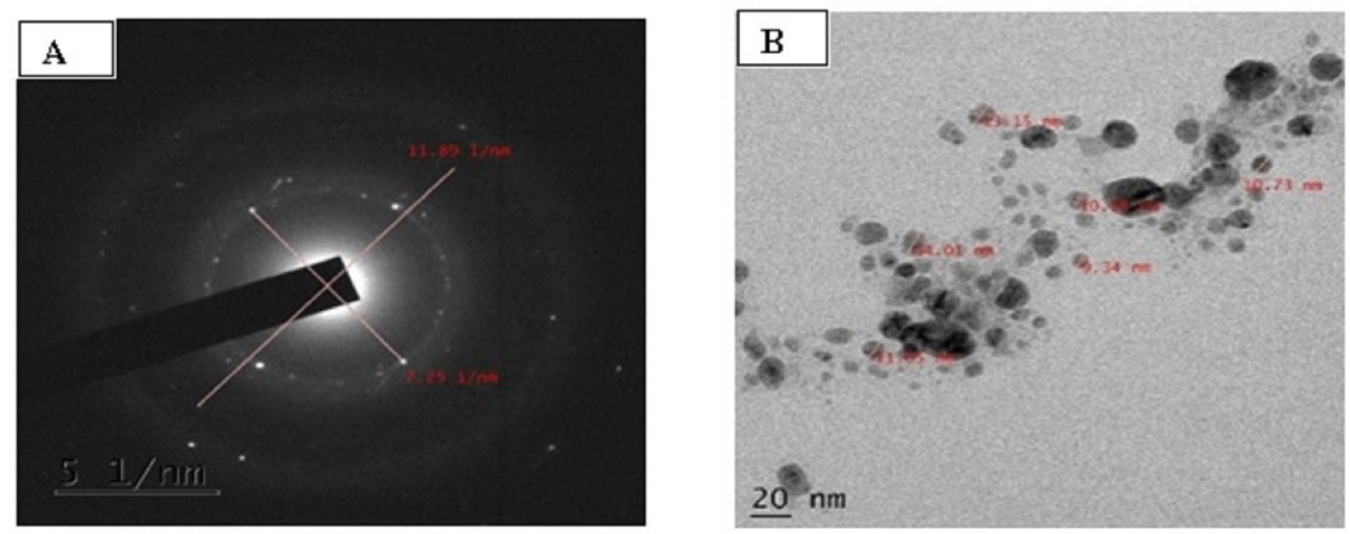

Figure 5. A: Selected area electron diffraction (SAED) pattern of AgNPs; B: High resolution transmission electron microscopic image (HR-TEM) of AgNPs (20nm).

Table 1. Effect of hydro alcoholic extracts and glimepiride on streptozotocin induced diabetic rats (chronic study).

\begin{tabular}{clcccc}
\hline \multirow{2}{*}{ Sr. No } & \multirow{2}{*}{ Treatment } & \multicolumn{4}{c}{ Serum glucose levels in mg/dl } \\
\cline { 3 - 5 } & & 3rd day & 5th day & 10st day & 14th day \\
\hline 1. & Normal & $97.91 \pm 6.296$ & $101.9 \pm 6.425$ & $95.80 \pm 5.975$ & $99.74 \pm 6.223$ \\
2. & Control & $340.5 \pm 9.107^{\mathrm{a}}$ & $331.0 \pm 9.599^{\mathrm{a}}$ & $334.1 \pm 9.088^{\mathrm{a}}$ & $318.5 \pm 10.54^{\mathrm{a}}$ \\
3. & Hydroalcoholic-Extract-250 mg/kg & $261.23 \pm 12.41^{* * *}$ & $221.1 \pm 11.21^{* * * *}$ & $156.2 \pm 14.45^{* * *}$ & $11.58^{* * *}$ \\
4. & Hydroalcoholic-500 $\mathrm{mg} / \mathrm{kg}$ & $224.17 \pm 9.21^{* *}$ & $169.1 \pm 13.11^{* * *}$ & $135.1 \pm 11.27^{* * *}$ & $09.11^{*}$ \\
5. & Glimepiride $[$ Standard] $(10 \mathrm{mg} / \mathrm{kg})$ & $198.5 \pm 12.20^{* *}$ & $188.0 \pm 4.898^{* * *}$ & $149.4 \pm 4.413^{* * *}$ & $90.26 \pm 5.203^{* * *}$ \\
\hline
\end{tabular}

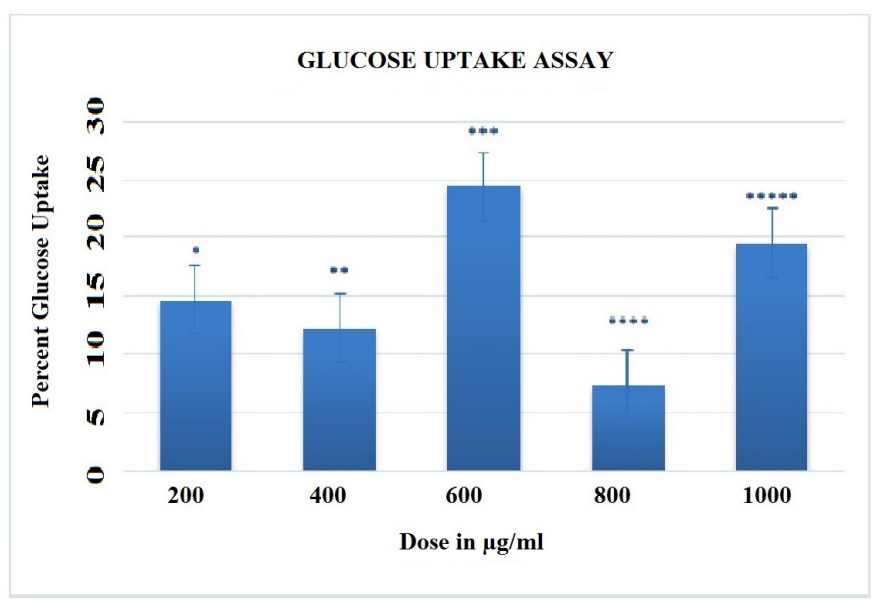

Figure 6. Glucose uptake assay of varying concentration of AgNP's. The error bars having different symbol are statistically significant at $p<0.01$ and $p<0.05$.

From Streptozotocin induced hyperglycemic (chronic study) data, the hydroalcoholic extract showed better tendency to decrease the blood glucose level on 14th day of treatment. Standard glimepiride antidiabetic drug was taken for comparison.

\section{In vitro antidiabetic activity}

\section{Glucose uptake assay}

The antidiabetic activities of AgNPs were assessed using the GOD-POD method of glucose uptake assay. This is simple enzymatic colorimetric method used for the quantitative determination of D-glucose in pharmaceuticals or biological samples. In this experiment, in presence of glucose oxidase

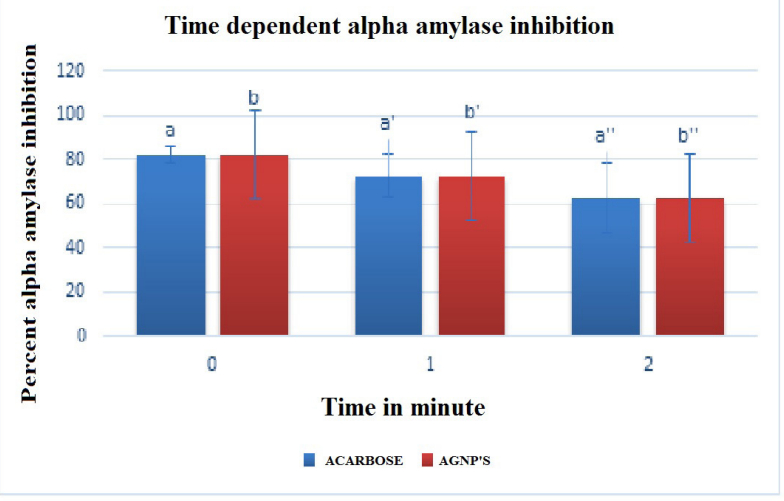

(A)

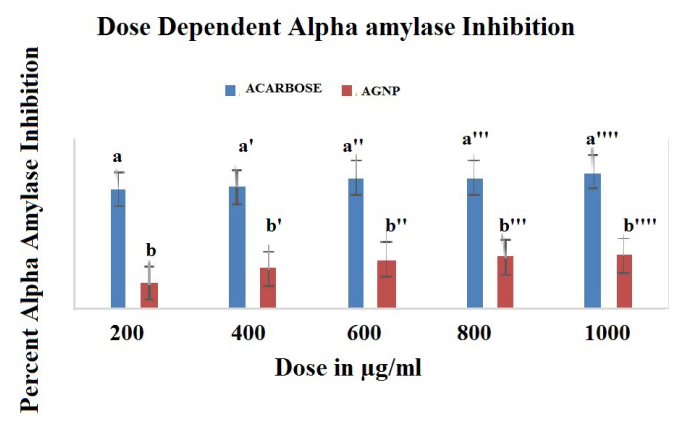

(B)

Figure 7. A) Time depenedent alpha amylase inhibition of AgNP's and Acarbose. B) Dose dependent alpha amylase inhibition of AgNP's and Acarbose. The error bars having different letters are statistically significant at $p<0.01$ and $p<0.05$. 
Table 2. Time dependent alpha amylase inhibition of AgNPs.

\begin{tabular}{ccccc}
\hline Sr. no. & Groups & Mean \pm Std. Dev. & Time & \% Inhibition \\
\hline 1. & Blank & 0.51 & & \\
2. & Control & 0.10 & 0 minute & \\
3. & Control & 0.13 & 1 minute & \\
4. & Control & 0.15 & 2 minutes & \\
5. & Standard & $0.07 \pm 0.008$ & 0 minutes & 86.27 \\
6. & Standard & $0.09 \pm 0.008$ & 1 minutes & 82.35 \\
7. & Standard & $0.11 \pm 0.016$ & 2 minutes & 78.43 \\
8. & AgNPs & $0.11 \pm 0.016$ & 0 minutes & 78.43 \\
9. & AgNPs & $0.19 \pm 0.016$ & 1 minutes & 62.74 \\
10. & AgNPs & $0.27 \pm 0.030$ & 2 minutes & 47.05 \\
\hline
\end{tabular}

Table 3. Dose dependent alpha amylase inhibition of AgNPs.

\begin{tabular}{ccccc}
\hline Sr. No. & Groups & Dose $(\boldsymbol{\mu g} / \mathbf{m l})$ & Mean \pm Std. Dev. & \% Inhibition \\
\hline 1 & Blank & & 0.58 & \\
2 & Standard & 200 & $0.17 \pm 0.004$ & 70.68 \\
3 & Standard & 400 & $0.16 \pm 0.004$ & 72.41 \\
4 & Standard & 600 & $0.13 \pm 0.008$ & 77.58 \\
5 & Standard & 800 & $0.13 \pm 0.008$ & 77.58 \\
6 & Standard & 1,000 & $0.11 \pm 0.009$ & 81.03 \\
7 & AgNPs & 200 & $0.49 \pm 0.016$ & 15.51 \\
8 & AgNPs & 400 & $0.44 \pm 0.016$ & 24.13 \\
9 & AgNPs & 600 & $0.41 \pm 0.016$ & 29.31 \\
10 & AgNPs & 800 & $0.40 \pm 0.020$ & 31.03 \\
11 & AgNPs & 1,000 & $0.39 \pm 0.020$ & 32.00 \\
\hline
\end{tabular}

enzyme, glucose is broken down into gluconic acid and hydrogen. Furthermore, peroxidase enzyme oxidizes hydrogen peroxide with four amino-antipyrine and four hydroxybenzoic acid to form pink colored quinone-imine dye. GOD-POD method was employed for determination of Glucose uptake measured in $\mathrm{mg} / \mathrm{dl}$. Data was expressed as mean \pm SEM. To assess the percentage increase in glucose uptake over controls, three separate experimental values were taken. The results of the in vitro glucose uptake analysis showed the $21.95 \%$ increase in glucose uptake at $1,000 \mu \mathrm{g} / \mathrm{ml}$ AgNPs as shown in Figure 6.

$\alpha$-amylase inhibitory assay

Time dependent $\alpha$ - amylase inhibitory assay

In vitro time dependent $\alpha$ - amylase inhibitory activity for synthesized AgNPs was investigated. Acarbose produced a concentration-dependent inhibition of $\alpha$ amylase enzyme. The results in Figure 7A and Table 2 shown that AgNPs exhibited activity in a time dependent manner and is comparable with positive controls acarbose. Thus AgNPs could be an effective a-amylase inhibitor. Data was expressed as mean \pm SEM Standard acarbose showed $78.43 \%$ alpha amylase inhibition at 2 minutes. Hydro alcoholic stem extract of C. grandis (L.) Voigt showed antidiabetic activity in vivo. It may be contributed to the involvement of phytochemicals like terpenes, triterpenes, flavonoids and alkaloids in hydro alcoholic extract. The natural product based $\alpha$-amylase inhibitor provides a potential therapeutic approach in diabetes mellitus.
Dose dependent $\alpha$ - amylase inhibitory assay

In dose dependent study, the AgNPs of 200, 400, 600, 800 , and $1,000 \mu \mathrm{g} / \mathrm{ml}$ were used. The standard acarbose of same concentration was used. From the Figure 7B and Table 3, it was seen that the AgNPs of $C$. grandis Voigt extract were tested on $\alpha$-amylase enzyme at $200,400,600,800$, and $1,000 \mu \mathrm{g} / \mathrm{ml}$ doses. And it was observed from the results that dose dependent inhibition of $\alpha$-amylase enzyme was remarkable but not produced better results compared to the standard. Dose dependent inhibition of AgNPs decreases while that of acarbose increases.

\section{CONCLUSION}

AgNPs play a crucial role in the context of biomedical sciences because of their excellent physical and chemical properties. In the present study, green synthesis of AgNPs of C. grandis (L.) Voigt stem extract was accounted for with its in vitro antidiabetic assessment. It was proved rapid, ecofriendly, and cost effective green synthesis of AgNPs with efficient In vitro antidiabetic activity over biological and physical methods. The nanoparticles can be used to improve therapeutic efficiency of drugs. As nanoparticles can be used as vehicle in drug transportation, this technique may be useful in the targeted drug delivery system. In vivo antidiabetic activity of hydroalcoholic extract were revealed the potential to reduce blood glucose in streptozotocin induced diabetic rats and in vitro studies demonstrated the significant capability of AgNPs to lessen the glucose uptake and inhibit alpha amylase enzyme. This green synthesis, method is competitive method over chemical and physical methods of nanoparticles and proved to have potential in biomedical and pharmaceutical sciences.

\section{LIST OF ABBREVIATIONS}

NPs: Nanoparticles; AgNPs: Silver nanoparticles; SAED: Selected area electron diffraction; FTIR: Fourier Transform Infrared Spectroscopy; TEM: Transmission Electron Microscopy; DNS: Di nitro salicylic acid; NaOH: Sodium Hydroxide; GOD-POD: Glucose Oxidase-Peroxidase.

\section{AUTHOR CONTRIBUTION}

Miss Momin Yasmin: Data handling, experiments design, draft preparation, writing Manuscript; Dr. Yeligar Veerendra: Supervision, study consultation, data analysis.

\section{CONFLICT OF INTEREST}

The authors declare that they have no conflict of interest.

\section{FUNDING}

There is no funding to report.

\section{ETHICAL APPROVAL}

The study was approved and conducted as per the norms of the Institutional Animal Ethics Committee (Appasaheb Birnale College of Pharmacy, Sangli) on 22 January 2018. Reference No. IAEC/ABCP/08/2017-18.

\section{REFERENCES}

Abou El-Nour KMM, Eftaiha A, Al-Warthan A, Ammar RAA. Synthesis and applications of silver nanoparticles. Arab J Chem, 2010; 3(3):135-40; doi:10.1016/j.arabjc.2010.04.008 
Banerjee A, Maji B, Mukherjee S, Chaudhuri K, Seal T. In vitro anti-diabetic and anti-oxidant activities of ethanol extract of tinospora sinensis. Int J Curr Pharm Res, 2017; 9(2): 42-7; doi:10.22159/ ijcpr.2017v9i2.17379

Benakashani F, Allafchian AR, Jalali SAH. Biosynthesis of silver nanoparticles using Capparis spinosa L. leaf extract and their antibacterial activity. Karbala Int J Mod Sci, 2016; 2(4):251-8; doi:10.1016/j. kijoms.2016.08.004

Chandran SP, Chaudhary M, Pasricha R, Ahmad A, Sastry M. Synthesis of gold nanotriangles and silver nanoparticles using Aloe vera plant extract. Biotechnol Prog, 2006; 22(2):577-83; doi:10.1021/bp0501423

Emam M, El Raey MA, Eisa WH, El-Haddad AE, Osman SM, El-Ansari MA, Rabie AGM. Green synthesis of silver nanoparticles from Caesalpinia gilliesii (Hook) leaves: antimicrobial activity and in vitro cytotoxic effect against BJ-1 and MCF-7 cells. J Appl Pharm Sci, 2017; 7(08):226-33. doi:10.7324/JAPS.2017.70831

Govindappa M, Hemashekhar B, Arthikala MK, Ravishankar Rai V, Ramachandra YL. Characterization, antibacterial, antioxidant, antidiabetic, anti-inflammatory and antityrosinase activity of green synthesized silver nanoparticles using Calophyllum tomentosum leaves extract. Results Phys, 2018; 9:400-8; doi:10.1016/j.rinp.2018.02.049

Gupta RN, Pareek A, Suthar M, Rathore GS, Basniwal PK, Jain D. Study of glucose uptake activity of Helicteres isora Linn. fruits in L-6 cell lines. Int J Diabetes Dev Ctries, 2009; 29(4):170-3; doi:10.4103/09733930.57349

Kharissova OV, Dias HVR, Kharisov BI, Pérez BO, Pérez VMJ. The greener synthesis of nanoparticles. Trends Biotechnol, 2013; 31(4):240-8; doi:10.1016/j.tibtech.2013.01.003

Lakshmanan G, Sathiyaseelan A, Kalaichelvan PT, Murugesan K. Plant-mediated synthesis of silver nanoparticles using fruit extract of Cleome viscosa L.: assessment of their antibacterial and anticancer activity. Karbala Int J Mod Sci, 2018; 4(1):61-8; doi:10.1016/j.kijoms.2017.10.007

Malapermal V, Botha I, Krishna SBN, Mbatha JN. Enhancing antidiabetic and antimicrobial performance of Ocimum basilicum, and Ocimum sanctum (L.) using silver nanoparticles. Saudi J Biol Sci, 2017; 24(6):1294-305; doi:10.1016/j.sjbs.2015.06.026
Meenatchi P, Purushothaman A, Maneemegalai S. Antioxidant, antiglycation and insulinotrophic properties of Coccinia grandis (L.) in vitro: possible role in prevention of diabetic complications. J Tradit Complement Med, 2017; 7(1):54-64; doi:10.1016/j.jtcme.2016.01.002

Nair SS, Kavrekar V, Mishra A. In vitro studies on alpha amylase and alpha glucosidase inhibitory activities of selected plant extracts. Eur J Exp Biol, 2013; 3(1):128-132.

Rai M, Yadav A, Gade A. Silver nanoparticles as a new generation of antimicrobials. Biotechnol Adv, 2009; 27(1):76-83; doi:10.1016/j. biotechadv.2008.09.002

Ramaswamy U, Mukundan D, Sreekumar A, Mani V. Green synthesis and characterization of silver nanoparticles using aqueous whole plant extract of Vernonia cinerea L. and its biological activities. Mater Today Proc, 2015; 2(9):4600-8; doi:10.1016/j.matpr.2015.10.080

Shah A, Latif-Ur-Rahman, Qureshi R, Zia-Ur-Rehman. Synthesis, characterization and applications of bimetallic (Au-Ag, Au-Pt, Au-Ru) alloy nanoparticles. Rev Adv Mater Sci, 2012; 30(2012): 133-149.

Stamplecoskie KG, Scaiano JC. Light emitting diode irradiation can control the morphology and optical properties of silver nanoparticles. J Am Chem Soc, 2010; 132(6):1825-7; doi:10.1021/ja910010b

Tamilselvan N, Thirumalai T, Elumalai E, Balaji R, David E, Pharmacognosy of Coccinia grandis: a review. Asian Pac J Trop Biomed, 2011; 1:S299-302; doi:10.1016/S2221-1691(11)60176-7

Varghese R, Almalki MA, Ilavenil S, Rebecca J, Choi KC. Silver nanopaticles synthesized using the seed extract of trigonella foenumgraecum L. and their antimicrobial mechanism and anticancer properties. Saudi J Biol Sci, 2019; 26(1): 148-54; doi:10.1016/j.sjbs.2017.07.001

How to cite this article:

Momin YH, Yeligar VC. Synthesis of Coccinia grandis (L.) Voigt extract's silver nanoparticles and it's in vitro antidiabetic activity. J Appl Pharm Sci, 2021; 11(08):108-115. 